\title{
Modeling ANd Simulation Of Field ORIENTED CONTROL INDUCTION MOTOR DRIVE AND INFLUENCE OF ROTOR RESISTANCE VARIATIONS ON ITS PERformanCE
}

\author{
Saji Chacko ${ }^{1}$, Dr. Chandrashekhar N.Bhende ${ }^{2}$, Dr. Shailendra Jain ${ }^{3}$ and Dr. R.K. \\ $\mathrm{Nema}^{4}$ \\ ${ }^{1}$ Research Scholar, ${ }^{3,4}$ Professor, Department of Electrical Engineering \\ Maulana Azad National Institute of Technology, Bhopal (MP), India and \\ ${ }^{2}$ Assistant Professor, School of Electrical Sciences Indian Institute of Technology \\ Bhubaneswar (Orissa), India
}

\begin{abstract}
Induction motor with rotor flux based indirect field oriented control is well suited for high performance applications due to its excellent dynamic behavior. The overriding feature of this control method is its ease of implementation and linearity of the torque versus slip characteristics. But, the indirect field oriented controller is sensitive to variations in motor parameters, especially variation in rotor time constant. This paper presents the modeling and analysis of a voltage controlled rotor flux based indirect field oriented control induction motor motion control system. with detailed analysis of controller design in discrete system. The influence of rotor resistance variation on the performance of drive like effect on speed, rotor flux and electromagnetic torque under different operating is also studied.
\end{abstract}

\section{KEYWORDS}

Induction motor (IM), Indirect rotor flux based Field Oriented Control (IRFOC), Sine Pulse Width Modulation (SPWM)

\section{INTRODUCTION}

Till the beginning of 1980's applications which require high speed holding accuracy, wide range of speed control and fast transient response used DC motor drives. Traditionally AC machines [1] were used in applications like fan, pump and compressor where only rough speed regulation is required and the transient response is not critical, but the advances in the field of power electronics has contributed to the development of control techniques [2] where DC machine like performance can be obtained in $\mathrm{AC}$ machines. These techniques are known as vector control techniques. Vector controlled techniques [3,4] can be classified as Direct/feedback field oriented control method (DFOC) and indirect/ feed forward method (IRFOC). The method depends on the determination of instantaneous rotor flux phasor position $\theta_{e}$ known as field angle or unit vector.

The main issue of vector control is its dependence on motor model and is therefore sensitive to the motor parameter variations $[5,6]$. The variations are mainly due to the saturation of the

DOI : 10.14810/elelij.2016.5103 
magnetizing inductance and the stator / rotor resistance due to temperature and skin effect. These variations lead to error on the flux amplitude and its orientation along the d-axis. The system thus becomes unstable and also increases the losses in the system. In general the field oriented control method most commonly used in industries is the indirect field oriented control where the orientation of the flux space vector is estimated using the slip signal and the measured speed. The feed forward adjustment of the slip signal requires knowledge of rotor resistance, rotor inductance and magnetizing inductance values and is estimated from the equivalent circuit model.

It has been observed that the variations of rotor resistance and therefore the rotor time constant is the most critical in indirect field oriented vector controlled drives [7, 8]. If care is not taken to estimate the change, the orthogonality between the synchronous frame $d_{e}-q_{e}$ variables is lost leading to cross coupling and poor dynamic performance of the drive system.

This paper will describe the details of the controller design in discrete system for a rotor flux based indirect field oriented controlled (IRFOC) induction motor drive [9-11] and the effect of rotor resistance variation on the drive performance.

The paper is organized as follows: Section 2 provides a brief overview of the dynamic model of Induction motor. Section 3 provides the function of the control blocks involved in the modeling of the vector controlled drive. Section 4 describes the design of controllers in discrete time domain. Section 5 details the simulation results of the IFOC and the effect of rotor resistance variations under different drive operating conditions and concluding remarks are given in Section 6.

\section{DYNAMIC MODEL OF INDUCTION MOTOR}

The control of an induction motor can be made similar to that of a DC machine with vector control technique, where it is possible to have independent control of flux and torque. In order to achieve it the mathematical model of the motor in a rotating reference frame has to be synchronized either to the stator, air gap or rotor flux vector. For this one should know the angle of the stator, air gap or rotor flux vector along with their magnitude.

The dynamic model of induction motor for rotor flux oriented vector control application can be written as follows

$$
\left[\begin{array}{c}
i d_{s e} \\
i q_{s e} \\
p_{\lambda d_{r e}} \\
\lambda q_{r e}
\end{array}\right]=\left[\begin{array}{cccc}
\frac{-R s}{\sigma L s} & \omega e & \frac{-L m}{L r \sigma L s} p & \frac{\omega e L m}{L r \sigma L s} \\
-\omega e & \frac{-R s}{\sigma L s} & \frac{-\omega e L m}{L r \sigma L s} & \frac{-L m}{L r \sigma L s} p \\
\frac{L m}{T r} & 0 & \frac{-1}{T r} & \omega s l \\
0 & \frac{L m}{T r} & -\omega s l & \frac{-1}{T r}
\end{array}\right]\left[\begin{array}{c}
i d_{s e} \\
i q_{s e} \\
\lambda d_{r e} \\
\lambda q_{r e}
\end{array}\right]+\left[\begin{array}{c}
\frac{v d_{s e}}{\sigma L s} \\
v q_{s e} \\
\sigma L s \\
0 \\
0
\end{array}\right]
$$

where $i d_{s e}, i q_{s e}$ are the stator currents and $\lambda d_{r e}, \lambda q_{r e}$ the rotor fluxes in $d_{e}-q_{e}$ frame. Similarly $R s, L s$, Rrand $L r$ are the stator résistance, stator self inductance, rotor resistance and the rotor self 
inductance. The rotor time constant is given as $T r=\frac{L r}{R r}$ and leakage inductance is $\sigma L s$ where $\sigma=$ $1-\frac{L m^{2}}{L s L r}$.

For rotor flux oriented control the rotor flux $\lambda r$ is directed along the $d$-axis and is equal to $\lambda d_{r e}$ and therefore $\lambda q_{r e}=0$. Thus the equation (1a) modifies to as shown below

$$
\left[\begin{array}{c}
i d_{s e} \\
p q_{s e} \\
\lambda d_{r e} \\
0
\end{array}\right]=\left[\begin{array}{cccc}
\frac{-R s}{\sigma L s} & \omega e & \frac{-L m}{L r \sigma L s} p & 0 \\
-\omega e & \frac{-R s}{\sigma L s} & \frac{-\omega e L m}{L r \sigma L s} & 0 \\
\frac{L m}{T r} & 0 & \frac{-1}{T r} & 0 \\
0 & 0 & 0 & 0
\end{array}\right]\left[\begin{array}{c}
i d_{s e} \\
i q_{s e} \\
\lambda d_{r e} \\
0
\end{array}\right]+\left[\begin{array}{c}
v d_{s e} \\
\sigma L s \\
v q_{s e} \\
\sigma L s \\
0 \\
0
\end{array}\right]
$$

From equation (1b) it can be seen that the $d_{e}-q_{e}$ axis voltage are coupled by the terms

$$
\begin{aligned}
& v_{d} \text { decoupling }=\omega e i q_{s e}-\frac{L m}{\operatorname{Lr} \sigma L s} p \lambda d_{r e} \\
& v_{q} \text { decoupling }=\omega_{e i d_{s e}}+\frac{\omega e L m}{L r \sigma L s}
\end{aligned}
$$

To achieve linear control of stator voltage it is necessary to remove the decoupling terms. These terms can be considered as disturbance and are cancelled by using a decoupled method that utilizes nonlinear feedback of the coupling voltage. The equation (1b) now modifies to (2a) as shown

$$
\left[\begin{array}{r}
i d_{s e} \\
p i q_{s e} \\
\lambda d_{r e}
\end{array}\right]=\left[\begin{array}{ccc}
\frac{-R s}{\sigma L s} & 0 & 0 \\
0 & \frac{-R s}{\sigma L s} & 0 \\
\frac{L m}{T r} & 0 & \frac{-1}{T r}
\end{array}\right]\left[\begin{array}{c}
i d_{s e} \\
i q_{s e} \\
\lambda d_{r e}
\end{array}\right]+\left[\begin{array}{c}
\frac{v d_{s e}}{\sigma L s} \\
v q_{s e} \\
\sigma L s \\
0
\end{array}\right]
$$

From equation (2a) the transfer function for the d-q current controllers and the flux controller of the vector controlled induction motor drives are as follows.

Current Controller for $\mathrm{d}$ axis

$\frac{i d_{s e}}{v d_{s e}}=\frac{\frac{1}{\sigma L_{s}}}{s+\frac{R_{s}}{\sigma L_{s}}}$

Current controller for $\mathrm{q}$ axis is given as

$$
\frac{i q_{s e}}{v q_{s e}}=\frac{\frac{1}{\sigma L_{S}}}{s+\frac{R_{S}}{\sigma L_{S}}}
$$


and similarly the flux controller transfer function is given

$\frac{\lambda d_{r e}}{i d_{s e}}=\frac{\frac{L_{m}}{T_{r}}}{s+\frac{1}{T_{r}}}$

The electromagnetic torque equation of a rotor flux oriented IFOC is given as

$T_{e}=\frac{3}{2} \frac{P}{2} \frac{L_{m}}{L_{r}} i q_{s e} \lambda d_{r e}$

Also $T_{e}=T_{l}+\frac{J d \omega_{r}}{d t}+\mathrm{B} \omega_{r}$

where $T_{l}, J, B$ and $\omega_{r}$ are the load torque, moment of inertia, coefficient of friction and rotor speed respectively. From equation (2e) and (2f) the transfer function of the speed controller is given as

$\frac{\omega_{r}}{T_{e}}=\frac{\frac{1}{J}}{s+\frac{B}{J}}$

The block diagram of the vector control system is shown in figure (2). It can be inferred from equation $(2 \mathrm{~b})$ to $(2 \mathrm{~g})$ that the controller transfer functions are all first order system and therefore the design process for these four controllers are same.

\section{MODELING OF VOLTAGE CONTROLLED IM DRIVE}

The block diagram of an indirect rotor flux oriented speed control of induction motor is shown in Figure.1.

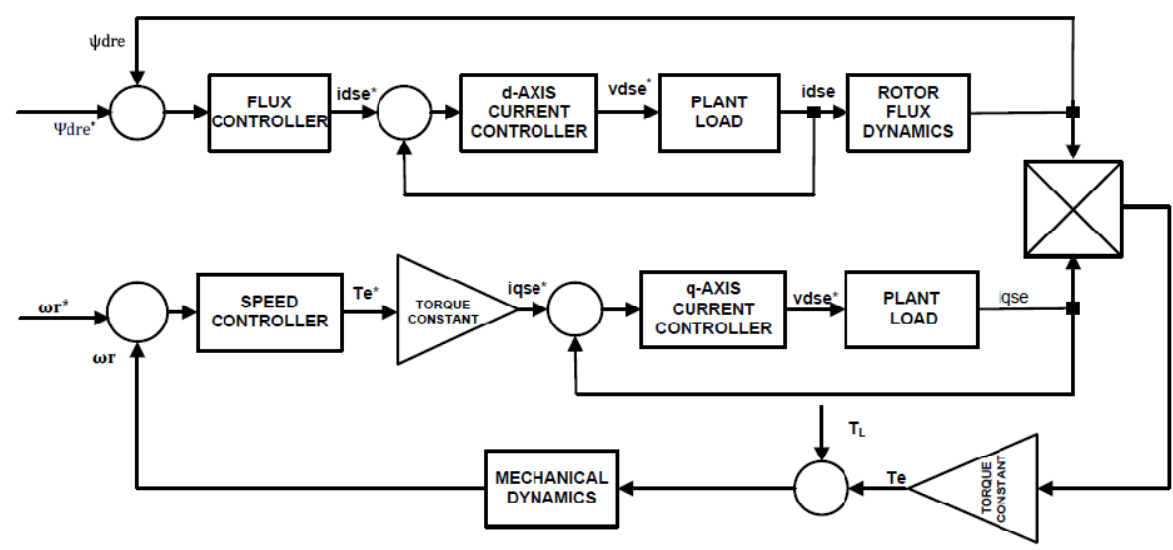

Figure.1 Block diagram of a vector controlled IFOC drive

The scheme consists of the current control loop within the speed control loop. The scheme uses four PI controllers, namely the speed controller, flux controller and the d-q axis current controller 
and the determination of its gain parameter are discussed in the section below. To avoid cross coupling between the $d-q$ axis voltages, voltage decoupling equations (1c) \& (1d) are adjusted with the output of the controllers to obtain good current control action. The d-axis and q-axis reference voltages $v d_{\text {ref }}$ and $v q_{\text {ref }}$ thus obtained are transformed to the stationary i.e. stator reference frame with the help of field angle $\theta_{e}$. In indirect field oriented control the rotor flux position $\theta_{e}$ is obtained by integrating the synchronous speed $\omega_{e}$ which in turn is obtained by summing the measured rotor speed $\omega_{r}$ and the slip speed $\omega_{s l}$. The slip speed $\omega_{s l}$ is given as

$$
\omega_{s l}=\frac{L_{m} i q_{s e} R_{r}}{L_{r} \lambda_{r}}
$$

From equation (3a) it is observed that the slip speed depends on the resistance and self inductance of the motor rotor and whose values are initialized during motor start up.

The two phase voltage $v_{d s s}$ and $v_{q s s}$ in the stator reference frame are then transformed to three phase stator reference voltages $v_{a}, v_{b}, v_{c}$ which acts as modulating voltage for the modulator ,which uses the sine-triangle pulse width modulation (SPWM) scheme. The modulator output which is in the form of pulses is used to drive the IGBT with anti-parallel diode acting as switches for the conventional two level voltage source inverter (VSI).

The stator currents are measured and transformed to the synchronous reference frame as shown in Figure. 2. The $d-q$ axis currents are used as feedback signals for the current controller. The $d$ - axis current $i_{d s e}$ is passed through a low pass filter with time constant equal to rotor time constant $T_{r}$ to obtain the rotor flux which acts as feedback to the flux controller.

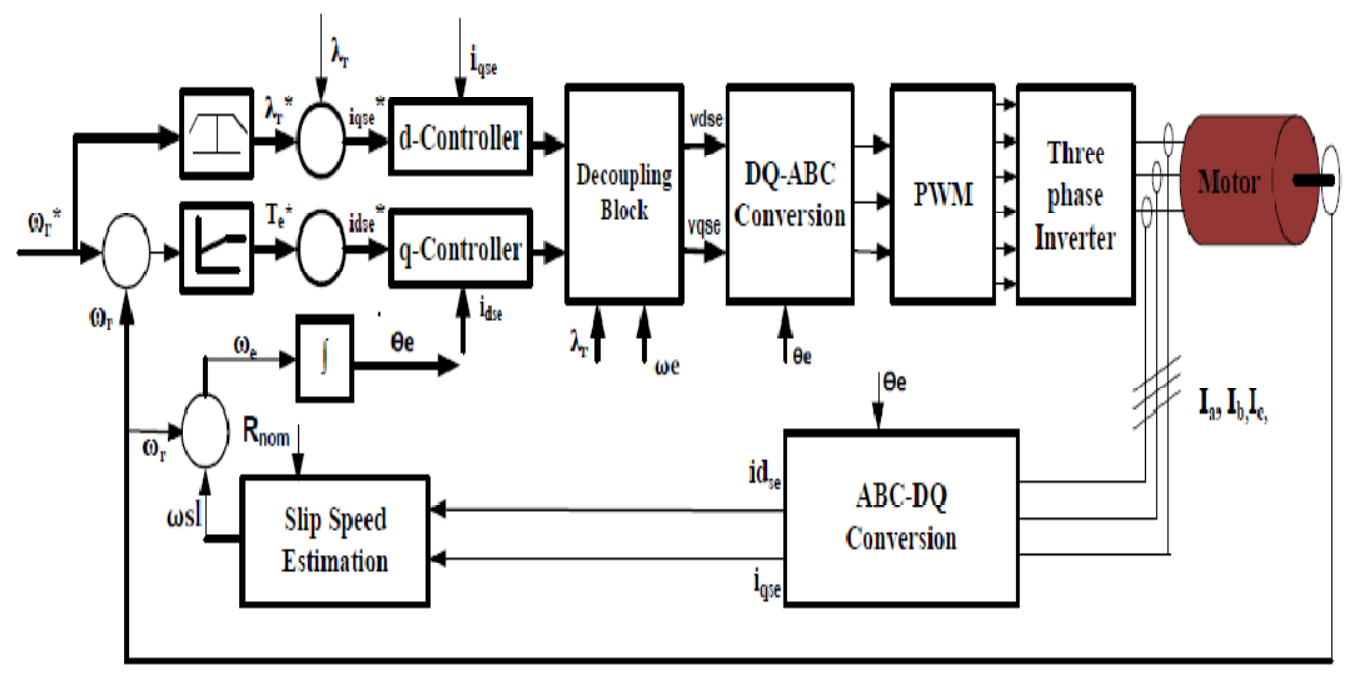

Fig. 2 Voltage controlled IFOC drive. 


\section{DESIGN OF CONTROLLER IN DISCRETE SYSTEM}

The block diagram of a current controlled system is shown in Fig. 3 consists of the PI controller given as $C(s)=\frac{k_{p}\left(s+\frac{k_{i}}{k_{p}}\right)}{s}$ and $G i(s)$ as given by equation (2b). In the design of the current controller the processing delay $e^{-S T_{S}}$ and the power converter delay $k_{P W M e^{-s T_{S}}}$ modeled as first order transfer is not considered to simplify the design procedure where $k_{P W M}$ is the gain of the power converter and $T_{S}$ is the sampling time

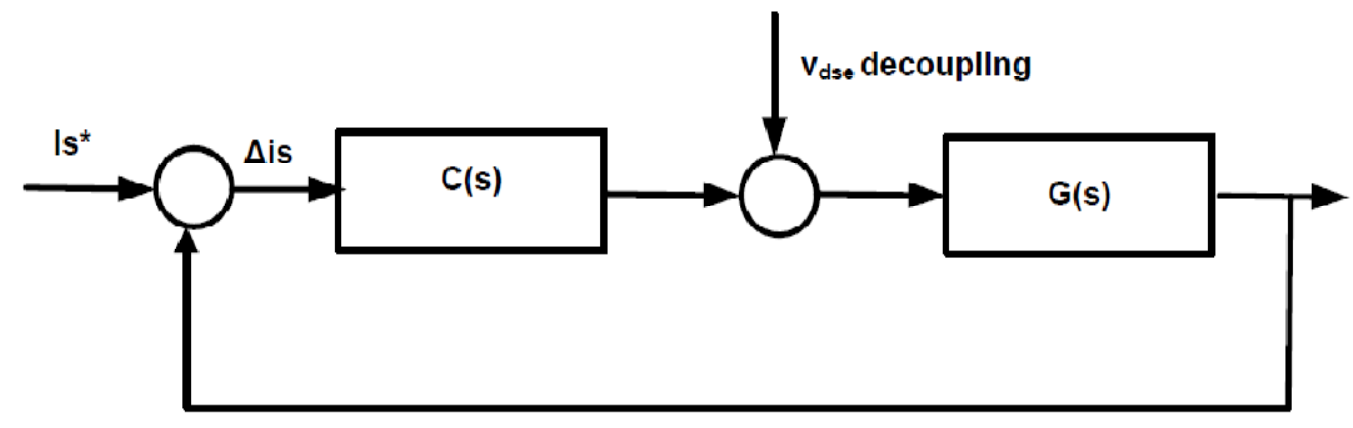

Figure. 3 d-q current controller in time domain system

For real time applications the system is controlled in discrete time domain and therefore the PI controller in $Z$ domain whose block can be derived as $C_{z}=\frac{\left(k_{p}+k_{i} T\right) z-k_{p}}{z-1}$. The block diagram of the discrete control system for the current loop is shown in Fig.4. The parameters $k_{p}$ and $k_{i}$ of the discrete controller are obtained by the following steps.

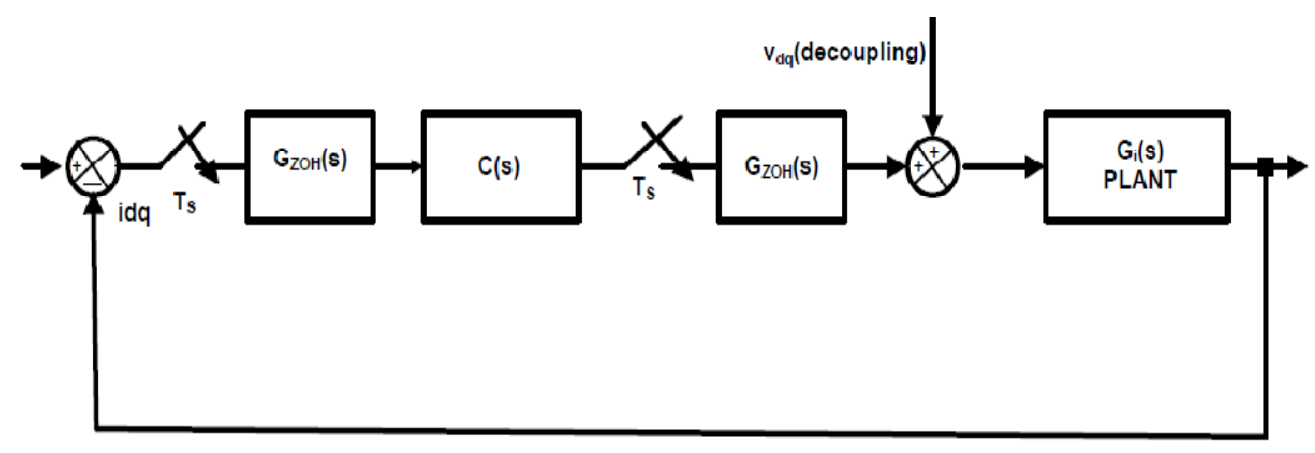

Fig.4 d-q Current controller in discrete time domain

First calculate the open loop transfer function of the plant. Second derive the loop gain of the control system using pole-zero cancellation method and lastly obtain the controller parameters from the closed loop transfer function. 
Electrical and Electronics Engineering: An International Journal (ELELIJ) Vol 5, No 1, February 2016

Step-1 - Calculate the open loop transfer function of the plant

The open loop transfer function of the plant in $Z$ domain can be derived as

$\frac{i_{s}(z)}{\Delta i_{S}(z)}=C(z) \cdot Z\left[G_{Z O H}(s) \cdot G_{i}(s)\right]$

Where, $G_{Z O H}(s)=\frac{1-e^{-T_{S}}}{s}$ and the numerator $1-e^{-T_{S}}$ in $Z$ domain can be written as $1-z^{-1}$. Similarly $C(z)$ can be rewritten as

$C(z)=k_{p}+k_{i} T \frac{\left(z-\frac{k_{p}}{k_{p}+k_{i} T}\right)}{z-1}$

and $G_{i}(s)$ as given by equation (2b).

Substituting equation (4b) in equation (4a), the equation modifies to

$\frac{i_{s}(z)}{\Delta i_{s}(z)}=k_{p}+k_{i} T \frac{\left(z-\frac{k_{p}}{k_{p}+k_{i} T}\right)}{z-1} \cdot \frac{z-1}{z} Z\left[\frac{G_{i}(s)}{s}\right]$.

The $\mathrm{Z}$ transformation of $\frac{G_{i(s)}}{s}$ is given as $\frac{1}{\sigma L_{S} X}\left[\frac{\left(1-e^{-X T}\right)}{\left(z-e^{-X T}\right)}\right] \cdot \frac{z}{z-1}$, where $X=\frac{R_{S}}{\sigma L_{S}}$.

Finally the open loop transfer function becomes

$\frac{i_{S}(z)}{\Delta i_{S}(z)}=k_{p}+k_{i} T \frac{\left(z-\frac{k_{p}}{k_{p}+k_{i} T}\right)}{z-1} \cdot \frac{1}{\sigma L_{s} X}\left[\frac{\left(1-e^{-X T}\right)}{\left(z-e^{-X T}\right)}\right]$

Step 2-Deriving the loop gain of the transfer function using pole-zero cancellation method

From equation (4c) using pole-zero cancellation we can write

$\frac{k_{p}}{k_{p}+k_{i} T}=e^{-X . T}$

Simplifying and solving the equation we get $k_{p}=\frac{e^{-X . T}}{1-e^{-X . T}} \cdot k_{i} T$

Substituting $k_{p}$ in equation (4c) we get

$\frac{i_{s}(z)}{\Delta i_{S}(z)}=k_{p}+k_{i} T \cdot \frac{1}{\sigma L_{S} X}\left[\frac{1-e^{-X T}}{z-1}\right]$

Step-3 Determining the controller parameters for a given bandwidth 
The closed loop transfer function of the system as shown in fig. 4 can be obtained as

$\frac{i_{S}(z)}{i_{S_{*}}(z)}=\frac{k_{p}+k_{i} T\left(1-e^{-X T}\right)}{\sigma L_{S} X} \cdot \frac{1}{z-1+\frac{k p+k_{i} T\left(1-e^{-X T}\right)}{\sigma L_{S} X}}$

In discrete time domain the bandwidth of the first order system is given as

$\frac{1-e^{-B W \cdot T}}{z-e^{-B W \cdot T}}$

Equating the above two equations i.e. $(4 \mathrm{~g}) \&(4 \mathrm{~h})$ we get

$$
k_{p}+k_{i} T=\frac{\sigma L_{s} X\left(1-e^{-B W \cdot T}\right)}{1-e^{-X T}}
$$

Substituting the value of $k_{p}$ from equation (4d) in the above equation we get the integral gain

$$
k_{i}=\frac{\sigma L_{S} X\left(1-e^{-B W \cdot T}\right)}{T} \text { and the proportional gain } k_{p}=\frac{e^{-X T} \sigma L_{S}\left(1-e^{-B W \cdot T}\right)}{1-e^{-X T}}
$$

Similarly following the steps as described for the $i_{d-q}$ current controller, the gains for the flux controller and the speed controller obtained are given in Table-I.

Table.1 Proportional $\left(k_{p}\right)$ and Integral $\left(k_{i}\right)$ Gains of PI Controller

\begin{tabular}{|l|c|c|}
\hline \multicolumn{1}{|c|}{ PI Controller } & $\boldsymbol{k}_{\boldsymbol{p}}$ & $\boldsymbol{k}_{\boldsymbol{i}}$ \\
\hline Speed control loop & 1.295 & 0.2967 \\
\hline Flux control loop & 110.6 & 1083.5 \\
\hline Inner $d_{e}-q_{e}$ current loops & 98.61 & 9087.04 \\
\hline
\end{tabular}

\section{RESULTS AND DISCUSSION}

A simulation model of voltage controlled IRFOC as shown in Figure.2 is developed in a Matlab/Simulink environment to ascertain the effectiveness of the IRFOC drive based on the controller parameter values given in Table-I. The parameters and ratings of the test motor are given in Appendix-I. The carrier wave shape is triangle in nature with the switching frequency kept at $10 \mathrm{KH}_{\mathrm{z}}$. The drive is run under three different operating conditions typical of its requirement for industrial applications. The drive is first operated keeping speed and load torque constant exhibiting the condition of a lathe drive which requires constant speed operation. From Figure 5 it could be concluded that the drive could attain the speed reference kept at $1000 \mathrm{rpm}$ in five seconds with the developed load torque matching with the set load torque. Second the motor is run under variable speed condition with the load torque remaining constant depicting the condition of crane motor drive. From Figure 6 it could be inferred that the proposed drive actual rotor speed could match the variable speed reference with adequate accuracy. It is also seen that from the Figure. 7 during the time interval 15-20sec the motor is at standstill holding the full 
load torque. The third and final drive operating condition exhibits the drive requirement for crusher drives used in mining industry. It is observed from Figure. 8 and 9 that during load changes the actual speed could track the reference speed showing the robustness of the drive controllers.

Simulation studies were also carried out to determine the effect in rotor resistance changes on the performance of the IFOC drive. The rotor resistance variation during drive operation is mainly due to temperature and skin effect. These uncertainties lead to error on the flux amplitude and its orientation along the d-axis. The system thus becomes unstable and also increases the losses in the system. The drive is run at a constant speed of $1000 \mathrm{rpm}$ with constant load torque of $5 \mathrm{Nm}$. At $\mathrm{t}=12 \mathrm{sec}$ the step increase in rotor resistance from $R_{\text {nom }}$ to 1.5 times $R_{\text {nom }}$ was initiated by connecting the three phase resistor bank controlled externally to the rotor of the slip ring induction motor. Similarly a step decrease in rotor resistance from $R_{\text {nom }}$ to $0.6^{*} R_{\text {nom }}$ is obtained by changing the magnitude of the instrumented rotor resistance value. It is seen that the increase/decrease in rotor resistance has resulted in sudden changes in the motor actual flux with its value increasing from $0.936 \omega \mathrm{b}$ to $1.195 \omega \mathrm{b}$ with increase in rotor resistance and decreasing from $0.936 \omega \mathrm{b}$ to $0.6 \omega b$ respectively as seen from Figure. 10 and 11. It is also seen from Figure.12 that the electromagnetic torque developed by the motor has also reduced slightly with an increase in rotor resistance at $\mathrm{t}=12 \mathrm{sec}$ and also there is a dip in a rotor speed from $1000 \mathrm{rpm}$ to $996 \mathrm{rpm}$ as observed in Figure.13. Similarly a substantial dip in rotor speed almost by nine rpm from its reference value was also observed in Figure. 14 for step decrease in rotor resistance. The effect of rotor resistance variation on the following parameters of the IFOC drives were also studied namely the rotor flux $\lambda_{r}, i q_{s e}$ the current component of torque and the motor input power ,$P$. The abscissa of Figure.15 indicates the ratio of $\frac{R_{r}}{R_{\text {rnom }}}$ and is varied from $0.5<\frac{R_{r}}{R_{\text {rnom }}}<1.5$. The ordinate indicates the normalized value of rotor flux, q-axis current component of torque and the motor power input. It is seen from figure that apart from the increase in rotor flux which may lead to motor saturation, the increase in rotor resistance from its nominal value has less impact on $i q_{s e}$ and the motor input power with their normalized value reaching to 0.8 and 1.2 respectively. On the other hand with decrease in actual resistance the rotor flux decreases to its normalized value of 0.4. In a way the decrease in rotor flux results in decrease in core losses especially the increase in drive efficiency when it is operating under no load condition, but on the other hand it is seen that under rated load condition the current component of torque and the drive power input increases significantly with its normalized value reaching to 1.8 and 1.5 respectively.

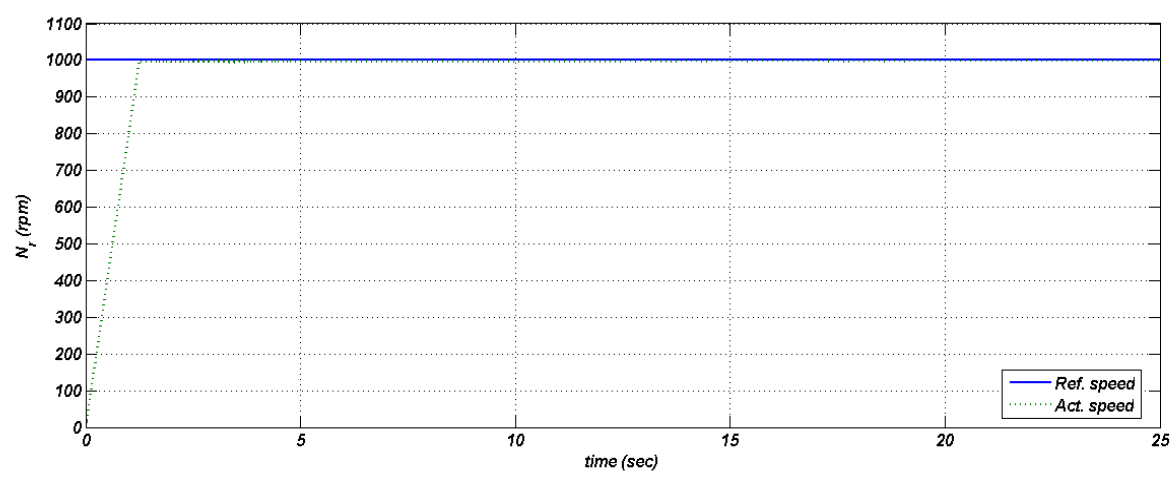

Figure 5. Tracking of contant reference rotor speed for constant load torque, $\mathrm{T}_{\mathrm{L}}=4 \mathrm{Nm}$ 
Electrical and Electronics Engineering: An International Journal (ELELIJ) Vol 5, No 1, February 2016

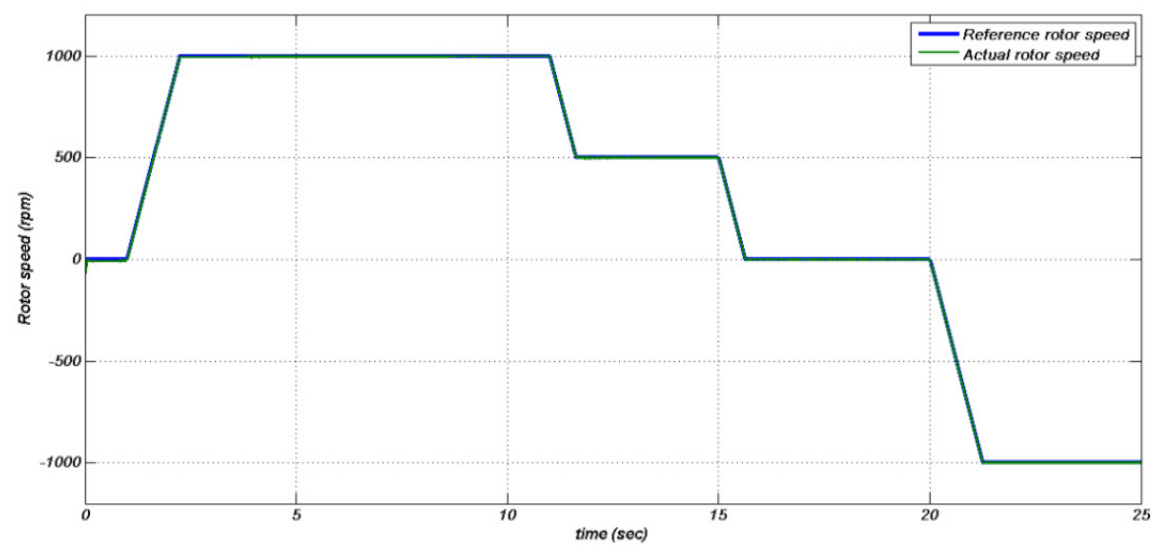

Figure 6. Tracking of variable rotor reference speed with load torque constant

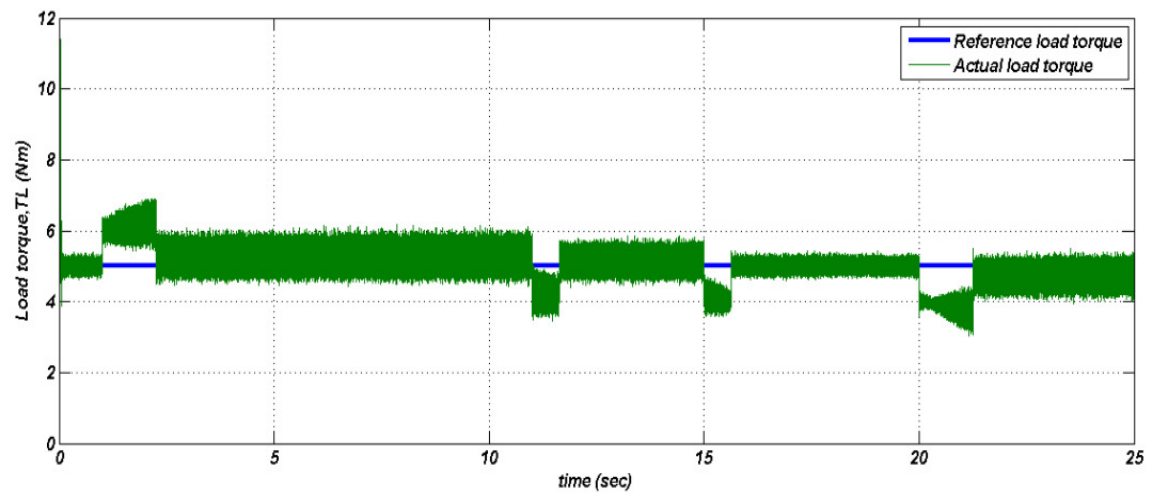

Figure 7. Devoloped load torque at variable rotor speed for $T_{L}=4 \mathrm{Nm}$

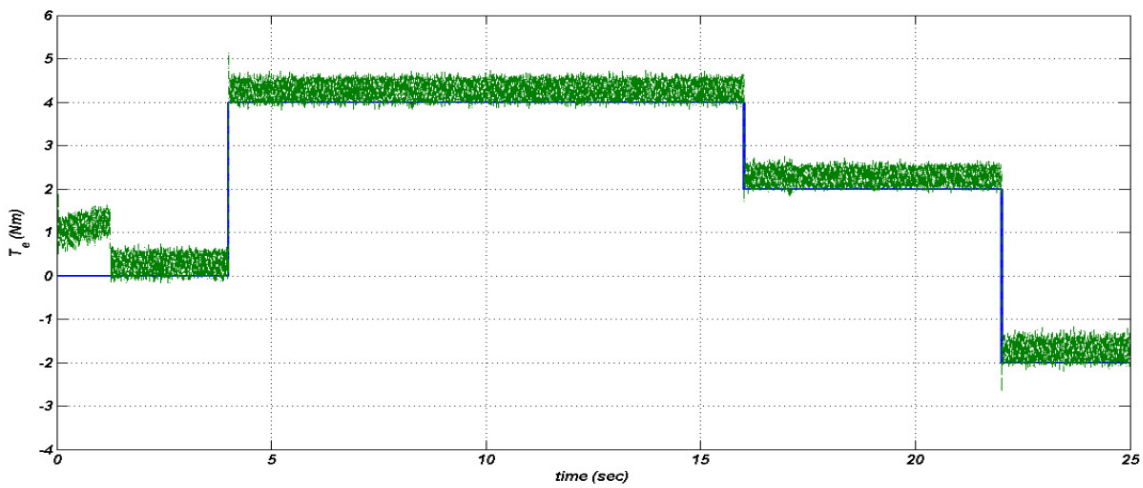

Figure 8.Developed load torque at constant rotor speed N=1000rpm 
Electrical and Electronics Engineering: An International Journal (ELELIJ) Vol 5, No 1, February 2016

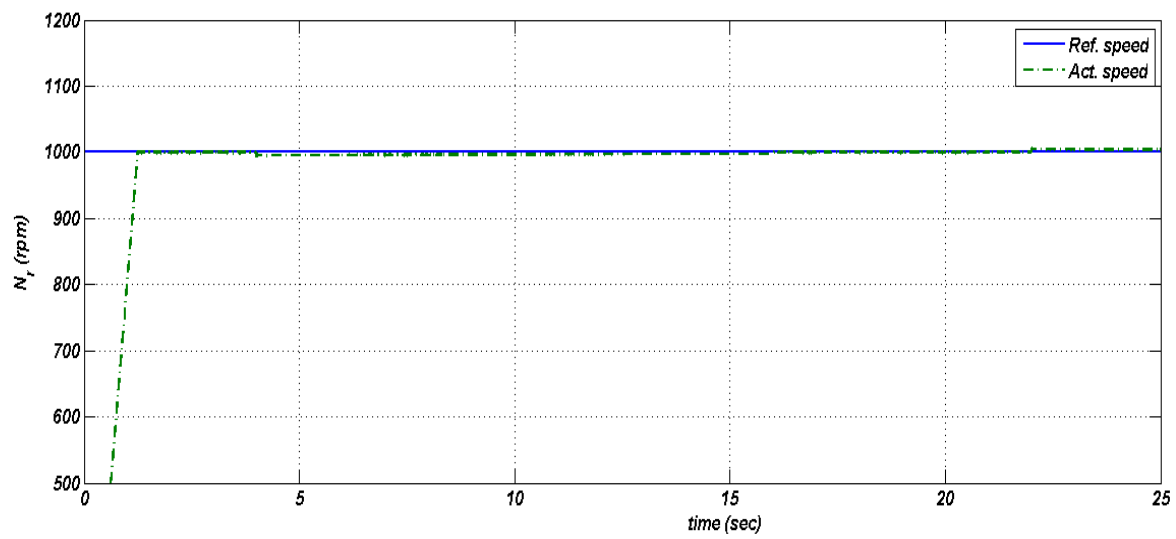

Figure 9. Trackng of constant rotor reference speed for variable load torque

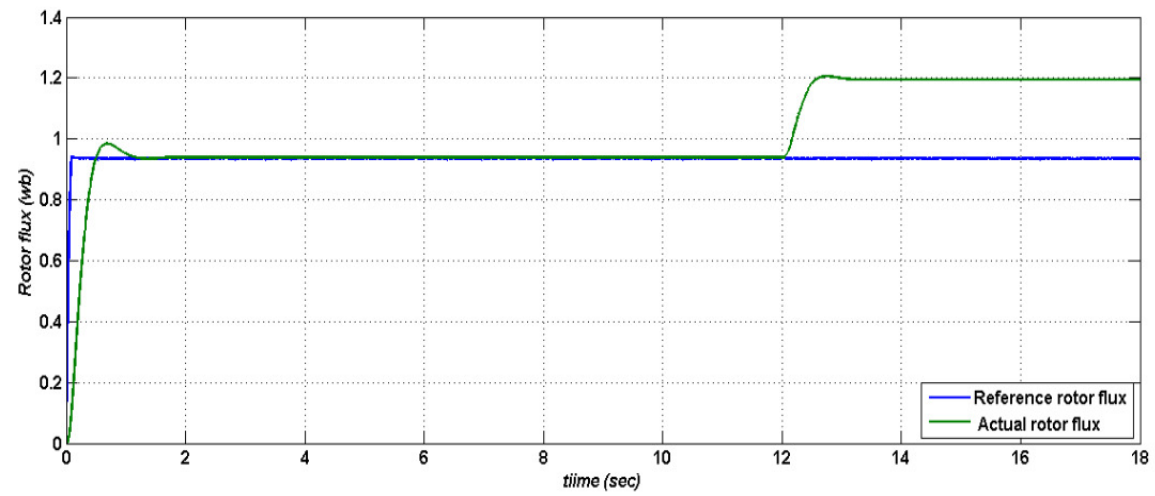

Figure10. Effect on actual rotor flux $\lambda_{r}$ for step increase in $R_{r}$ to $1.5^{*} R_{\text {nom }}$ at $\mathrm{t}=12 \mathrm{sec}$

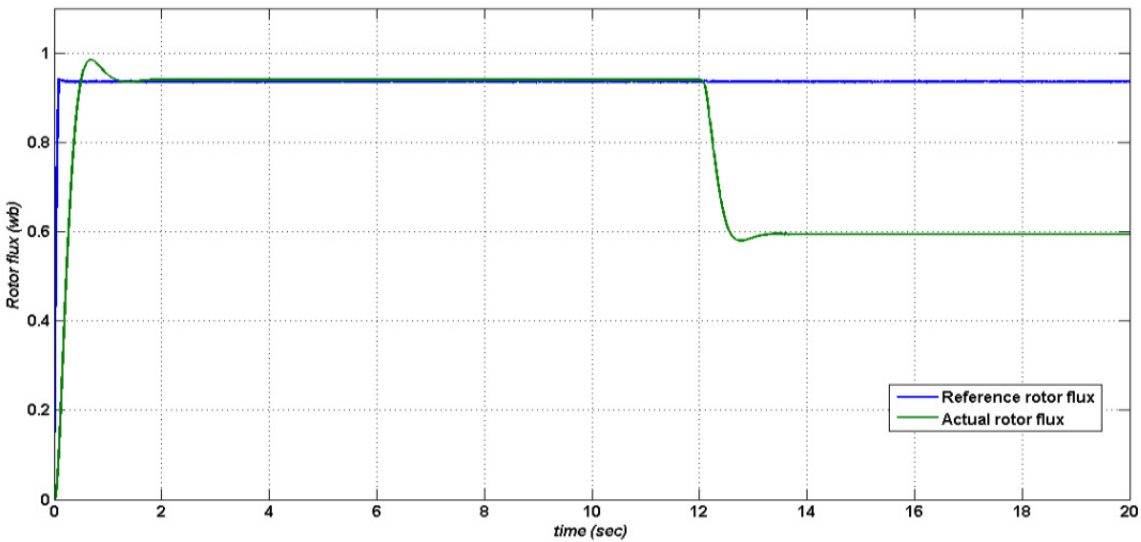

Figure11. Effect on actual rotor flux $\lambda_{r}$ for step decrease in $R_{r}$ to $0.6 * R_{\text {nom }}$ at $t=12 \mathrm{sec}$ 
Electrical and Electronics Engineering: An International Journal (ELELIJ) Vol 5, No 1, February 2016

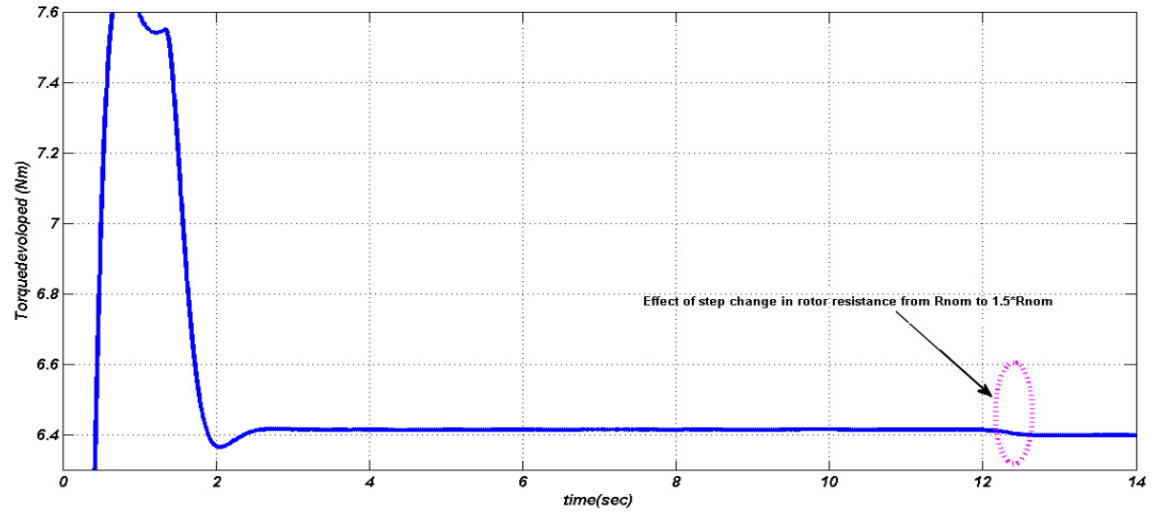

Figure12. Effect on torque developed, $T_{e}$ for step change in $R_{r}$ to $1.5 * R_{\text {nom }}$
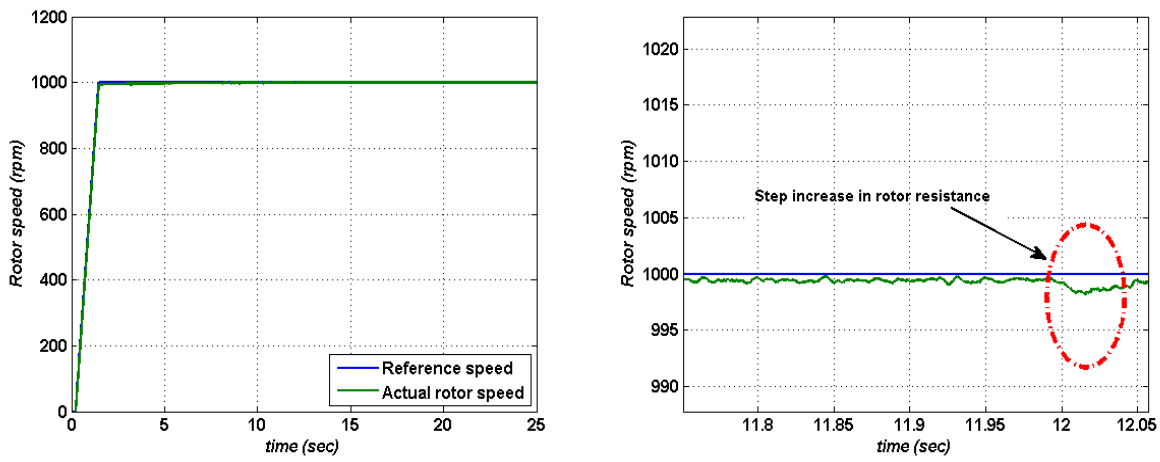

Figure13. Effect on actual rotor speed tracking for step increase in $R_{r}$ to $1.5 * R_{n o m}$
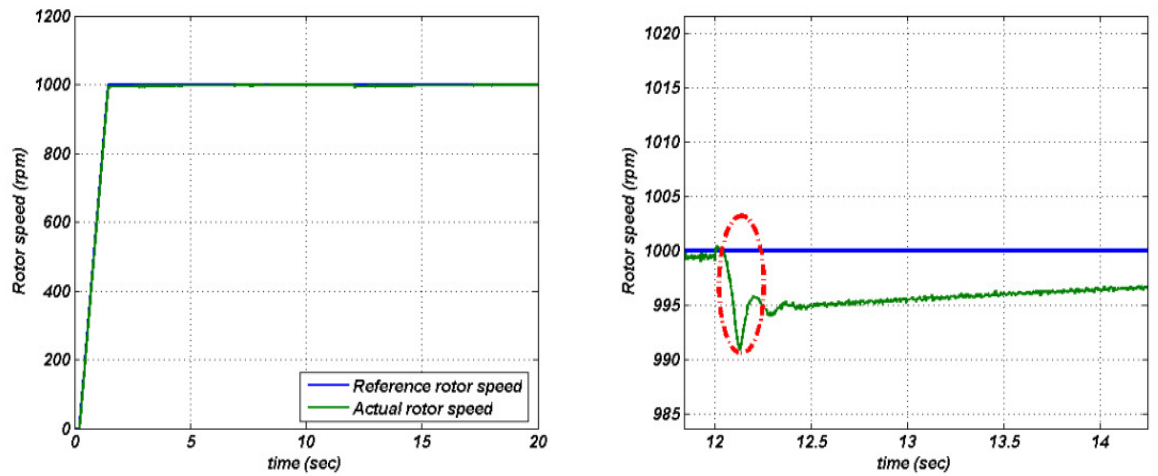

Figure14. Effect on actual rotor speed tracking for step decrease in $R_{r}$ to $0.6^{*} R_{\text {nom }}$ 


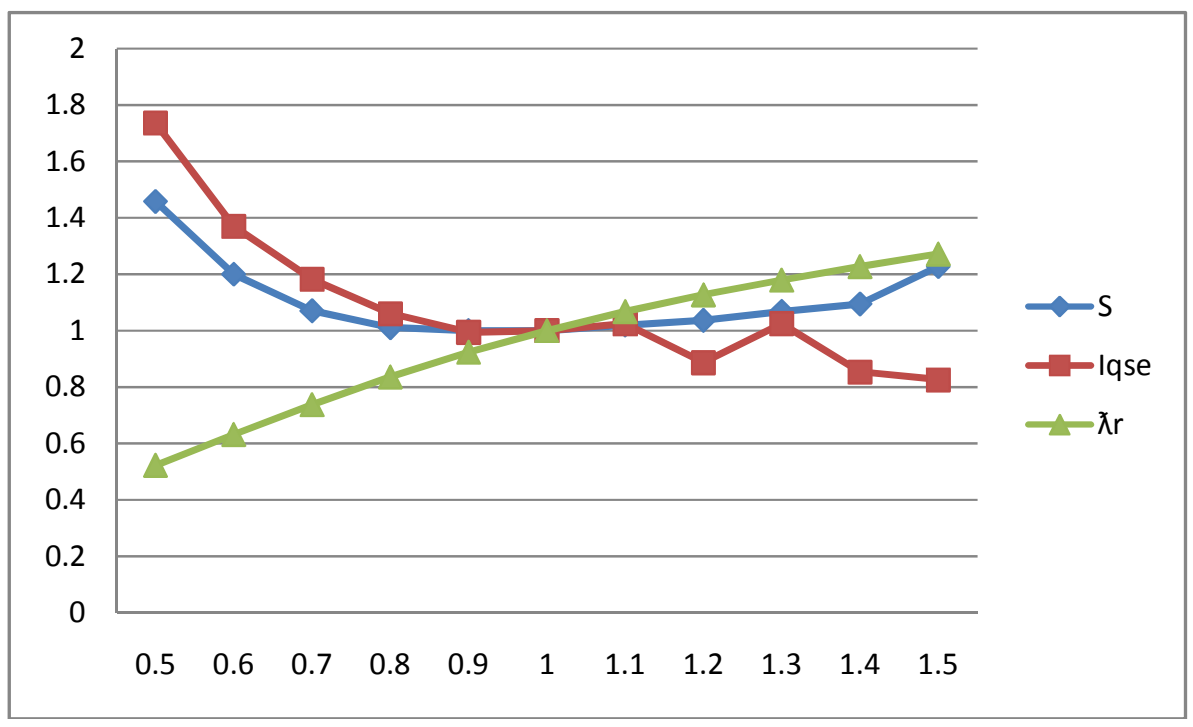

Figure15. Effect of rotor resistance variation from $0.5<\frac{R_{r}}{R_{\text {nom }}}<1.5$ on $\lambda_{r_{\text {, }}} i q_{s e}, P$

\section{CONCLUSION}

The rotor flux based indirect field oriented controller for induction motor drive fed by voltage source inverter is presented. The analysis for obtaining the PI controller parameters in discrete time system based on state space representation provides a link between induction machine modeling and vector controller. The development provides a simple approach in design and implementation of vector control technique for real time application. The effect of rotor resistance variation on the performance of the indirect rotor flux oriented induction motor drive is also investigated.

APPENDIX-I

Parameters of the IM used

\begin{tabular}{|c|c|}
\hline Parameters & Values(units) \\
\hline Power & $0.746 \mathrm{KW}$ \\
\hline Voltage & $415 \mathrm{~V}$ \\
\hline Stator current & $1.8 \mathrm{Amp}$ \\
\hline Speed $(\mathrm{rpm})$ & $1450 \mathrm{rpm}$, \\
\hline Stator Resistance $\left(\mathrm{R}_{\mathrm{s}}\right)$ & $10.75 \Omega$ \\
\hline Rotor Resistance $\left(\mathrm{R}_{\mathrm{r}}\right)$ & $9.28 \Omega$ \\
\hline Self Inductance $\left(\mathrm{L}_{\mathrm{s}} / \mathrm{L}_{\mathrm{r}}\right)$ & $0.5318 \mathrm{H}$ \\
\hline Moment of Inertia $(\mathfrak{l})$ & $0.011787 \mathrm{kgm} 2$, \\
\hline Friction coefficient $(\mathrm{B})$ & $0.0027 \mathrm{Nm} / \mathrm{rad} / \mathrm{sec}$ \\
\hline
\end{tabular}


Electrical and Electronics Engineering: An International Journal (ELELIJ) Vol 5, No 1, February 2016

\section{REFERENCES}

[1] John. W. Finch (2008) "Controlled AC Electrical drives" IEEE Trans. on Industrial Electronics, vol.55, No.2.

[2] B.K.Bose (2009). "Power Electronics and motor drives, Recent Progress and Perspectives." IEEE Transactions.on Industrial Electronics, Vol.56, No.2..

[3] F.Blaschke (1972). "The Principle of field orientation as applied to the new TRANSVECTOR closed loop control system for rotating field machine." Siemens Rev. Vol.34, pp. 217-220.

[4] Satoshi Ogasawara, H. Akagi, Akira Nabae (1988) "The Generalized theory of Indirect vector controlled AC machines.", IEEE Transactions on Industry Applications , Vol.24, No.3.

[5] K.B Nordin, D. W. Novotny (1985) “The Influence of Motor Parameter Deviations in Feed forward Field Orientation Drive Systems.” IEEE Transactions on Industry Applns.,Vol.1A-21,No.4.

[6] R.Krishnan,, F.C. Doran (1987) "Study of parameter sensitivity in high performance and inverter fed Induction motor drive system." IEEE Transactions on Industry Applications. Vol. IA-23 No.4 pp. 623-635

[7] R. Krishnan, A.S. Bhardawaj (1991) “A Review of Parameter sensitivity and adaptation in Industrial vector controlled Induction motor drive system”. IEEE Trans. on Power Electronics, Vol.6, No.4 .

[8] Hamid.A. Toliyat, Emil Levi, Mona Raina (2003) "A Review of RFO Induction motor parameter Estimation Technique." IEEE Transaction on Energy Conversions, Vol.18, No.2..

[9] B.Robyns, P.A. Sente, H.A. Buyse, F.Labrique (1999) “ Influence of Digital Current Control Strategy on the Sensitivity to Electrical Parameter Uncertainities of Induction Motor Indirect FieldOriented Control”. IEEE Transactions on Power Electronics. Vol. 14, No.4..

[10] Y S Lai (2003) "Machine Modeling and Universal Controller for Vector-Controlled Induction Motor Drives." IEEE Transactions on Energy Conversion, Vol. 18, No.1.

[11] Y.S. Lai, Y. T. Chang (2001)"Design and Implementation of Vector-Controlled Induction Motor Drives Using Random Switching Technique with Constant Sampling Frequency." IEEE Transactions on Power Electronics, Vol.16 No.3.

\section{AUTHORS}

Saji.T. chacko was born in Chattisgarh, India. He is a research scholar at Maulana azad National Institute of technology, Bhopal, (M.P), India. His area of research interest is Power Electronics and drives, Application of soft computing techniques for estimation and fault detection in Electric Drives.

Chandrakant. N. Bhende was born in Nagpur, Maharashtra, India He got his $\mathrm{PhD}$ degree from Indian Institute of Technology, Delhi, India in 2008 and thereafter did his Post Doctoral Research from University of Wollongong He is currently Assistant Professor, School of Electrical Sciences, Indian Institute of Technology, Bhubhaneshwar, Orissa, India. He is the author of 10 International journals His area of research interest includes Power Quality, Custom Power Devices, Renewable Energy sources and application of Soft computing Techniques in Power systems

Shailendra Jain was born in Madhya Pradesh (M.P), India in 1968. He got his Ph.D. degree from Indian Institute of Technology, Roorkee, India, in 2003, and the PDF from the University of Western Ontario, London,ON, Canada, in 2007. He is Professor in the Department of Electrical Engineering, Maulana Azad National Institute of Technology, Bhopal, M.P, India, He is the author of more than 70 Journals and 50 conference papers in National and International Publication like IEEE, Elsevier etc and reviewer of National
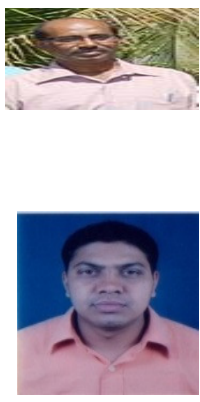
and International Journals. 
Electrical and Electronics Engineering: An International Journal (ELELIJ) Vol 5, No 1, February 2016

Rajesh Kumar Nema was born in Madhya Pradesh (M.P) India in 1963. He got his PhD degree from Bhopal University, Bhopal, India in 2004.Received "Colombo award" under Cultural Exchange programme "Indo-UK REC Project". He is Professor in the Department of Electrical Engineering, Maulana Azad National Institute of Technology, Bhopal, M.P, India,He is the author of more than 7 Journals and 50 conference papers in National and International Publication. His principle areas of research interest are Power Electronics, Solar Photovoltaics, Instrumentation,Distributed Generation. Multilevel Inverters, Microprocessor and DSP.

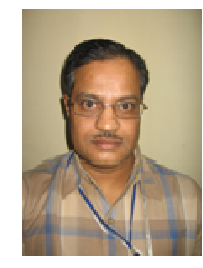

